\title{
Dedication of hands to nursing: A ceremony of caring
}

\author{
J ulia Ball, Thayer Wilson McGahee \\ School of Nursing, University of South Carolina Aiken, Aiken, USA \\ Correspondence: Thayer Wilson McGahee. Address: University of South Carolina Aiken School of Nursing, 471 University \\ Parkway, Aiken, SC 29801, USA. Email: thayerm@usca.edu.
}

Received: September 6, 2012

Accepted: January 18, 2013

Online Published: March 27, 2013

DOI : 10.5430/jnep.v3n10p58

URL: http://dx.doi.org/10.5430/jnep.v3n10p58

\section{Abstract}

Formerly, nursing schools held capping ceremonies for nursing students before their first clinical experience. Since nurses no longer wear caps, capping ceremonies with their rite of passage from regular student to student nurse have vanished. To bring back a ceremonial rite of passage for beginning student nurses, a ceremony of caring emphasizing the import of all that nurses' hands can convey as they provide nursing care was conceived. Undergirded by Jean Watson's Theory of Caring, the Hand Dedication Ceremony is an act of caring provided to first semester nursing students before their first clinical experience with patients. During the ceremony, students are charged to allow their hands to be guided not only by their new knowledge and skills but also by their hearts and spirits to transform skilled nursing tasks into skilled holistic nursing care. Students formally dedicate their hands to nursing and human caring as faculty ceremonially wash, dry, and apply oil to the students' hands.

\section{Key words}

Nursing education, Watson, Hands, Ceremony, Caring

\section{I ntroduction}

There was a tradition of a capping ceremony for nursing students beginning their clinical experience that has vanished from most nursing programs in the USA since the majority of nurses no longer wear caps. This rite of passage from regular student to nursing student was a significant landmark in many programs, marking the beginning of students giving actual hands-on nursing care. To emphasize the import of all that nurses' hands can convey as they provide nursing care, the Hand Dedication Ceremony was conceived. Undergirded by Jean Watson's Theory of Caring, the ceremony is an act of caring provided to first semester nursing students before their first clinical experience with patients. During the ceremony, students are charged to allow their hands to be guided not only by their new knowledge and skills, but also by their hearts and spirits to transform skilled nursing tasks into skilled holistic nursing care. Students formally dedicate their hands to nursing and human caring as faculty ceremonially wash, dry, and apply oil to the students' hands. The aim of this article is to provide the history and background of nursing ceremonies, and describe the Dedication of Hands Ceremony and its significance to nursing.

\section{History and background}

The following describes a scene from nursing's history: Beginning student nurses were gathered together by their professors to participate in a very special ceremonial tradition designed not only as a rite of passage to mark the transition 
from student to student nurse but also to introduce and inspire student nurses to place the aspect of caring into the nursing skills and tasks they had learned in the skills laboratory. All the student nurses proudly wore their brand new nursing uniforms and a mood of excitement pervaded the atmosphere. The students were about to be crowned with the nurses' cap, symbolic of their formal acceptance as students into the nursing profession, and symbolic of the honor and privilege they would soon be granted as they left the confines of the nursing skills lab to provide nursing care to patients in the hospital. As the students left the ceremony, their smiling family members congratulated them, took photographs, and enjoyed the reception that followed. The following week, the student nurses donned their uniforms and caps and went to the hospital units for their first clinical experience. Once on their assigned units, the students were immediately recognized as part of the nursing profession by everyone: patients, their families, nursing staff, and physicians.

As the students studied and passed their level examinations, they were promoted and their caps were adorned with an additional stripe to denote their senior status. Finally, the big day dawned and the students were ready to graduate, receive their nursing school pins, and wear their new graduate nurse caps. Then, after passing what was then called "State Boards", the graduate was a registered nurse who continued to wear the nursing school pin and graduate nurses’ cap.

The cap had great symbolic meaning to the student nurses and also to the public. The public of the day knew immediately if a nurse had entered their hospital room by the uniform and the cap. However, in the nineteen eighties and nineties, caps lost favor with the profession and today nurses' caps are rarely seen. Unfortunately, along with the disappearance of nurses' caps went the tradition of the capping ceremony and the recognition of the rite of passage from regular student to student nurse.

The nursing cap is a traditionally feminine article of clothing. The cap is often thought to be originally constructed as part of a unique ideal of femininity and modesty within the primarily masculine structure of a hospital. It is also believed by some to represent the physical labor aspect of nursing and its relationship to domestic service ${ }^{[1]}$. Some historians believe the nursing cap has origins traced to nuns' veils that symbolized subordination and obedience ${ }^{[2]}$. Eventually, nursing cap designs became unique to a particular school or hospital. As early as the late 1800's, resistance to caps was becoming evident. Many perceived them as a sign of subservience, and ladies' caps in general were falling out of fashion. In the 1960's and 1970's, the tradition of wearing caps began to significantly subside. Nurses were assuming more diverse clinical roles and management positions, and the feminist movement was gaining strength. Nurses wished to "be identified by what they did, not by how they looked" (p.37) ${ }^{[1]}$. During this time, men were also beginning to gain in numbers in the nursing profession, and there was no logic in requiring women to wear caps and not to require it of men ${ }^{[3]}$. The departure from wearing a nursing cap has been partly attributed to infection control issues, but the feminist movement undoubtedly played a more significant role in its demise.

\section{Nursing education in the 2000s}

Although present day nursing faculty members do their utmost to impress the importance of caring to today's student nurses, there is nothing in most modern curricula to emphasize the rite of passage from regular student to student nurse and the enormity of the responsibility of the nursing profession to care for the public good. Nursing students as a whole do not have any rituals or ceremonies other than the pinning ceremony held on the day of graduation and the graduation ceremony itself. Because of the lack of symbolism and the desire to bring something to nursing students to replace the capping ceremony that meant so much to the generations of yesterday's nurses, the faculty of a southeastern university in the United States determined to provide a meaningful ceremony and begin a tradition for the students.

Ceremonies are spotlight events in our lives. Baptisms, bar/bat mitzvahs, graduations, and weddings are a few examples of meaningful ceremonies that socialize, stabilize, and reassure the participants, while conveying to the community that a rite of passage has been achieved. All ceremonies call for planning and special arrangements which include seating plans, 
special clothing for the participants, the presentation of something of meaning, the preparation of ceremony materiel such as rings, water, or candles, the use of formal speech during the ceremony, and a reception or gathering afterwards ${ }^{[4]}$.

The capping ceremony had all of these components, including the symbolic meaning of the cap. Once "capped", the student was recognized as a person who had the right to wear the symbol of the nursing profession. Symbolism invested the nursing cap with a meaning that everyone understood. The wearer was a nurse and all wearers could be expected to have similar human values and caring practices.

\section{Review of literature on nursing ceremonies}

A thorough search of the literature through CINAHL, other nursing databases, Google Scholar, JSTOR, and Projectmuse provided very little about nursing student academic ceremonies. The pinning ceremonies continue to be prevalent throughout the world, with the individual pin representing the particular nursing school and university. Many nursing schools refer to the pin as a badge, and the unique pin of each school is generally presented to students as they graduate and is worn with pride as a symbol of professional service ${ }^{[5]}$. Some universities now award the pin to first year nursing students as they embark on their first clinical placement ${ }^{[6]}$. Pinning ceremonies are commonly held in the United States, Canada, India, Philippines, England, Scotland, and Wales and often include the lighting of candles to signify light, hope, and comfort. Very little is published about these ceremonies except for what is found on individual university websites.

Other ceremonies for nursing students include presenting students with a lamp to symbolize service and caring ${ }^{[7]}$, and presenting students with a willow branch to signify strength, roots, and flexibility ${ }^{[8]}$. There are Healing Presence Ceremonies ${ }^{[9]}$, ceremonies of recognition and awards ${ }^{[10]}$, and in some schools, particularly in Japan, the capping ceremony continues ${ }^{[2]}$. The traditional white uniform of nursing also has a history of symbolism with professional expertise and the privilege of wearing this uniform was often a rite of passage for nurses who had completed their professional studies ${ }^{[11]}$.

\section{Evolution of the Dedication of Hands Ceremony}

The evolution of the Dedication of Hands Ceremony was slow. The objective was to create a ceremony with meaning that nurses, students, and the community would understand and remember, and live within a relatively tight budget. There are "blessing of hands" ceremonies for faith community nurses and nurse midwives, but no such established tradition for undergraduate nursing students. However, after consulting with several faith community nurses, it was determined that such a ceremony would work with modifications. The university at which this ceremony was introduced is a state university, and therefore should have a spiritual rather than a religious connotation. This ceremony evolved from several blessing of the hands ceremonies with all language pertaining to a specific religion or denomination removed. The initial plan included a ritual hand washing and drying of the students' hands by faculty members and application of oil. However, the faculty also wished to use a candle in the ceremony and serendipitously, a colleague from a sister university provided the symbolic link. Jeanne Watson had visited the sister university and presented the school of nursing with a candle. The candle had been lighted from another candle with which Watson had lighted candles for other nurses and nursing schools throughout the world. Since 1992, the light from Watson's original candle has been passed at least twice around the globe. Watson's candles represent a world-wide chain of light symbolizing the unity of nurses to each other and to their dedication and commitment to human caring ${ }^{[12]}$. The faculty colleague from the sister university presented the school of nursing with a candle lighted by the candle left by Watson, thus continuing the world-wide chain of light. After the candle was received, the Hand Dedication Ceremony was complete.

\section{The Hand Dedication Ceremony}

The Hand Dedication Ceremony began in the fall of 2006 and was conceived as a spiritual ceremony, rather than a religious ceremony, to encompass the American Nurses Association (ANA) Code of Ethics. The ceremony emphasizes the 
art and the science of nursing and the necessity for nurses to provide skilled evidence-based care with hands guided by the hearts and spirits of the students to promote healing in everyone they touch. The purposes of the ceremony are twofold: to begin to socialize nursing students to the nursing profession and ANA code of ethics, and to bring home the enormity of the responsibility of promoting healing through holistic nursing care for another human being. Conducted by four nursing faculty members, the ceremony is provided for all first semester nursing students after they have successfully completed five weeks in the nursing skills laboratory and before they go to the hospital for the first time to care for "real" as opposed to simulated patients. All students wear their uniform for the ceremony, and the ceremony begins with lighting of the Watson Candle, symbolizing the unity of nurses and their common commitment to human caring. The same candle is also lighted once again at the graduating pinning ceremony and each student receives a candle that is lighted from that flame, thus propagating the chain of light and reminding the students of their hand dedication ceremony and their commitment to human caring.

The importance of the work of each student's hands within the context of caring is emphasized during the ceremony. The following excerpt is from the text of the ceremony: "It is the hands that turn nursing tasks and skills into acts of nursing and human caring. It is the students' hands guided not only by their new knowledge and skills but also by their spirits and their hearts." Featured in the ceremony are acts of caring as faculty members ritually wash and dry the students' hands and then apply oil to the students' palms. As each student's hands are washed, the words, "May your hands provide fervent and skillful nursing care" are spoken. During the drying, the faculty member states, "May your spirit of compassion and gentleness guide your hands". Finally, oil is applied to the student's palms with the words, "May your hands bring comfort and promote healing to all who come into your care". The ceremony concludes with the nursing students and faculty members holding hands in a circle with the ceremony leader making the closing statement "Go in peace with the knowledge of the human and spiritual caring that your hands will convey”.

After ten consecutive incoming classes have dedicated their hands to nursing, the ceremony is now a tradition. The importance of the event is evidenced by the Chancellor's and Academic Vice Chancellor's presence at every ceremony and the presence of family members and friends of the students. Additionally, the event is regularly covered by the press and several letters and positive comments have been received from nurses and lay people in the community. The nursing students who have been a part of these ceremonies overwhelmingly indicate the significance and meaningfulness of it to them. There is a lot of positive emotion demonstrated during this ceremony as students begin to realize the potential impact their hands can have on their patients. Many of the upper class students who have already had their hands dedicated choose to attend this ceremony each semester in order to share this meaningful experience with their younger classmates, to demonstrate caring to their classmates, and to reflect once again on the significance of their hands and the caring nature of their profession.

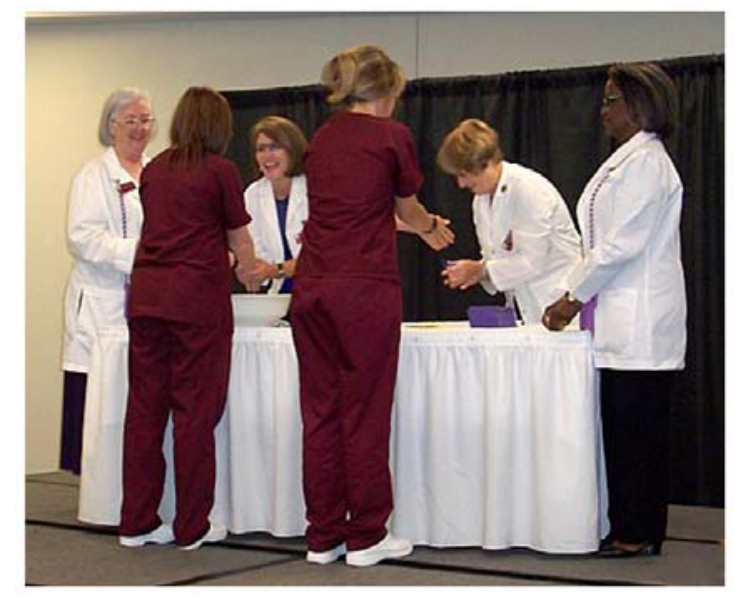

Figure 1. Photograph taken of the Hand Dedication Ceremony 


\section{The Hand Dedication Ceremony and Jean Watson's theory of caring}

The Dedication of Hands Ceremony was undergirded by Watson's Theory of Human Caring ${ }^{[13,14]}$. Caring is commonly espoused as a core value in nursing education. However, through experience, the authors have found that beginning nursing students often neglect to think about the need to include caring behaviors as they provide nursing care because they feel pressured to focus on the technical aspects of nursing they have learned in the skills laboratory. The Dedication of Hands Ceremony affords faculty members the opportunity to emphasize and model the concept of caring before students begin their clinical practice in the hospital. Tying together the theoretical perspectives of nursing learned in the classroom with clinical practice, the ceremony also emphasizes the need for a balance between a high-tech and a high-touch environment that Watson ${ }^{[15]}$ calls nurses to pursue.

Watson began formulating her theory of human caring in the 1970 's and it continues to evolve ${ }^{[13,14]}$. Her theory embraces spirituality, emphasizes the art and the science of nursing, and is appropriately used to convey to students the necessity for nurses to provide skilled, evidence-based care with hands guided by caring hearts and spirits as they promote healing in everyone they touch ${ }^{[14]}$. Watson believes that caring is a universal social phenomena that can only be effectively practiced interpersonally.

Watson's theory makes explicit the unique values, knowledge, and practices of human caring belonging to nursing, and is focused toward subjective inner healing processes and the life world of the experiencing person. The theory also seeks to balance the cure orientation and focus of the medical model to give nursing its distinct disciplinary, scientific, and professional position with itself and its public ${ }^{[14]}$.

Watson's original model was centered on the framework of ten carative factors that she described. The carative factors represented both feelings and actions that pertain to the nurse and the patient and included things to be felt, experienced, communicated, expressed, and promoted by every nurse ${ }^{[16]}$. However, finding these factors to be too static, Watson broadened her carative factors into what she now calls "clinical caritas processes" which suggest more open ways for caring to be considered. The clinical caritas processes bring dimensions of spirituality, love, and caring to the profession of nursing as art, science, and spirituality converge ${ }^{[14]}$. Watson's model of "transpersonal caring” ${ }^{[14]}$ allows for caring and love to come together in the nurse's work and life. Watson states that both nursing and the teaching of nurses are careers that are life-giving and life-receiving, enabling lifelong learning and growth. The model of transpersonal caring also embraces the concept of receiving a "call” to the nursing profession as identified by Nightingale with the commitment and covenantal ethic of service. A major contribution of Watson's theory is in sensitizing individual nurses to the humanistic aspects of nursing care and caring.

Connecting the spirit of the nurse with the spirit of another person, Watson's model opens up new possibilities for healing that go beyond physical healing, thus leaving behind the solely medical perspective. Watson states that because there is a mutual, intersubjective, and reciprocal relationship between the one caring (nurse) and the one being cared for (patient) ${ }^{[17]}$, her work is congruent with reports on health care and health educational reform that call for "centrality of caring-healing relationships" as being foundational for all health professional education and practice reform ${ }^{[14]}$.

Many hospitals and nursing schools in the USA have integrated caring theory for use as a model of care within their organizations ${ }^{[18-20]}$. Gallup polls place nursing as the number one profession with respect to honesty and ethics, and Watson ${ }^{[21]}$ attributes this acknowledgement of the nursing profession as reinforcement of the importance of sustaining the ethic of caring in nursing. Using Watson's theory to guide the Dedication of Hands Ceremony brings meaning to the theory, helps to make the theory relevant and useful in practice, and illustrates the integral role of caring in the nurse's professional life. The ceremony is an act of transpersonal caring by faculty members to the students as they meet one-to-one, hand-to-hand, spirit-to-spirit during the caring moments of the ceremony. The faculty members and the students are interconnected in a process that it is hoped will be transmitted to all those with whom the students have contact, so beginning a ripple effect of caring that will continue to infinity. 


\section{Conclusion}

Nurses must be able to combine skilled technical tasks with love and caring to promote healing through a deeper level of professional and spiritual practice. Rituals associated with ceremonies have a long tradition in nursing education. From the literature, it appears that nursing schools continue to place value on ceremonies and the symbols represented in them. Although pinning ceremonies are the most prevalent, there are universities that are developing other unique and meaningful traditions for their students. The Dedication of Hands Ceremony has served to unite the faculty and students around the School's shared and published values of caring and diversity, and is a symbol of the synthesis of technical tasks and caring. It has proven to be extremely meaningful to both students and faculty, and is a tradition that will continue for years to come.

\section{References}

[1] Bates. C. The nurse's cap and its rituals. Dress. 2010; 36: 21-40. http://dx.doi.org/10.1179/036121110X12789489457704

[2] Rika, S. \& Noriko, U. The image of nurses expressed by caps, and feminism perspective. What affected the changing in UK and USA. Science Links Japan. 2002; 25(2): 87-99.

[3] Stokowski, L. A. The demise of the nurse’s cap. Medscape. 2011 Aug; 10: 1-3.

[4] Bolman, L. G. \& Deal, T. E. Reframing organizations: Artistry, choice, and leadership (4th ed.). San Francisco: Jossey-Bass. 2008.

[5] Rode, M. W. The nursing pin: symbol of 1,000 years of service. Nursing Forum. 1989; 24(1): 15-7. PMid:2694101 http://dx.doi.org/10.1111/j.1744-6198.1989.tb00813.x

[6] Ferguson, M. K., Harvey, L, McKale, Waring, J., Platt, N. \& Reid, D. Pinning our hopes on the future. Canadian Nurse. 2008 ; 9: 9.

[7] Bethel college dedicates level I nursing students. 2007; ISNA Bulletin. May, 8.

[8] Burman, M. E., Hart, M., Conley, V. M., Caldwell, P. \& Johnson, L. The willow ceremony: Professional socialization for nurse practitioner students background. Journal of Nursing Education. 2007; 46(1): 48-48.

[9] Coffman, S. Healing presence ceremony in nursing education. International Journal for Human Caring. 2007; 11(4): 52-56.

[10] Lee, C. J., Idczak, S., Moon, J. \& Borwn-Scott, N. Strong minds, healing hands, and compassionate hearts: Developing a contemporary and creative twist on tradition. Nursing Education Perspective. 2006; 27(1): 10-11.

[11] Catanzaro, A. M. Beyond the misapprehension of nursing rituals. Nursing Forum. 2002; 37(2): 17-27. PMid:12244862 http://dx.doi.org/10.1111/j.1744-6198.2002.tb01194.x

[12] Watson, J. Post modern nursing and beyond. New York: Churchill Livingstone. 1999.

[13] Watson, J. Nursing: The philosophy and science of caring. Boston: Little Brown. 1979.

[14] Watson, J. Theory evolution. 2006. Available from: http://www2.uchsc.edu/son/caring/content/evolution.asp

[15] Watson, J. Nursing: Human science and human care. A theory of nursing. New York: National League for Nursing. 1988.

[16] Marriner, A. Nursing theorists and their work. St. Louis: C. V. Mosby Co. 1986.

[17] Watson, J. Caring theory as an ethical guide to administrative and Clinical practices. Nursing Administration Quarterly. 2006; (30)1: 48-55. http://dx.doi.org/10.1097/00006216-200601000-00008

[18] Gramling, L. \& Nugent, K. Teaching caring within the context of health. Nurse Educator. 1988; 23(2): 47-51. http://dx.doi.org/10.1097/00006223-199803000-00018

[19] Ryan, L. A. The journey to integrate Watson's caring theory with a clinical practice. International Journal of Human Caring. 2005; 9(3): 26-30.

[20] Watson, J. \& Foster, R. The attending nurse caring model: integrating theory, evidence and advanced caring-healing therapeutics for transforming professional practice. Journal of Clinical Nursing. 2003; 12: 360-365. PMid:12709110 http://dx.doi.org/10.1046/j.1365-2702.2003.00774.x

[21] Watson, J. 30th anniversary invited editorial reflecting on Law. 2006. 